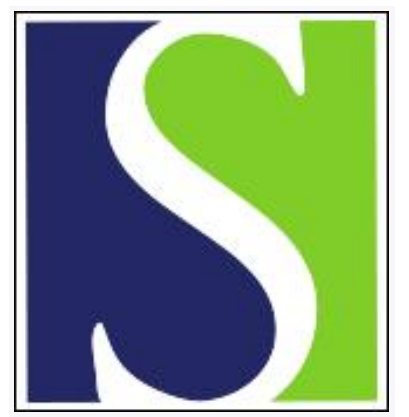

Scand J Work Environ Health 2016;42(6):490-499

https://doi.org/10.5271/sjweh.3598

Published online: 05 Oct 2016, Issue date: 01 Jun 2016

Work ability index and perceived work ability as predictors of disability pension: a prospective study among Finnish municipal employees

by Jääskeläinen A, Kausto J, Seitsamo J, Ojajärvi A, Nygård C-H, Arjas E, Leino-Arjas $P$

We utilized longitudinal data on both the work ability index (WAI) and the work ability score (WAS) to predict disability pension (DP) among men and women. We also took into account the effect of job content on the associations. Based on the results, WAS can be considered a good alternative to WAl in the prediction of DP.

Affiliation: Finnish Institute of Occupational Health, PO Box 40, Fl-00251 Helsinki, Finland. paivi.leino-arjas@ttl.fi

Refers to the following texts of the Journal: 2009;35(1):1-5

2010;36(5):404-412 2014;40(4):428-431 2014;40(5):473-482

The following articles refer to this text: 2018;44(2):134-146;

2021;47(1):22-32; 2022;48(7):569-578

Key terms: disability pension; disability retirement; early retirement; Finland; Finnish municipal employee; perceived work ability; predictor; predictor of disability pension; prognostic risk marker; prognostic tool; prospective study; sensitivity; specificity; WAl; WAS; work ability; work ability index; work ability score

This article in PubMed: www.ncbi.nlm.nih.gov/pubmed/27706492 


\title{
Work ability index and perceived work ability as predictors of disability pension: a prospective study among Finnish municipal employees
}

\author{
by Anne Jääskeläinen, PhD, ${ }^{1}$ Johanna Kausto, PhD, ${ }^{1}$ Jorma Seitsamo, PhD, ${ }^{1}$ Anneli Ojajärvi, PhD, ${ }^{1}$ \\ Clas-Håkan Nygård, PhD, ${ }^{2}$ Elja Arjas, PhD, ${ }^{3}$ Päivi Leino-Arjas, MD, PhD ${ }^{1,2}$
}

\begin{abstract}
Jääskeläinen A, Kausto J, Seitsamo J, Ojajärvi A, Nygård C-H, Arjas E, Leino-Arjas P. Work ability index and perceived work ability as predictors of disability pension: a prospective study among Finnish municipal employees. Scan J Work Environ Health. 2016;42(6):490-499. doi:10.5271/sjweh.3598
\end{abstract}

\begin{abstract}
Objectives We analyzed the work ability index (WAI) and its first item (work ability score, WAS) - and subsequent four-year changes thereof - as predictors of disability pension (DP).

Methods We linked survey responses of 5251 Finnish municipal employees, aged 44-58 years, to pension and death register data until 2009. Job content (physical, mental, or mixed) was based on observation. Baseline (1981) WAI was divided into poor ( $<27)$, moderate (28-36), and good/excellent ( $>37)$ and WAS into poor $(0-5)$, moderate (6-7), and good/excellent (8-10). Four-year changes in these scores were classified as strong decline $\left(<\right.$ lowest $15^{\text {th }}$ percentile), slight decline, and no change/improved. Cox regression and receiver operating characteristic (ROC) analysis were used.
\end{abstract}

Results During follow-up, 2057 subjects were granted DP. Compared to those with good/excellent WAI, the hazard ratio (HR) for DP related to moderate and poor WAI, respectively, was 2.0 (95\% CI 1.8-2.2) and 5.0 (95\% CI 4.4-5.6), adjusted for sociodemographic variables and job content. For WAS, the HR were 1.8 (95\% CI $1.6-2.0)$ and $3.4(95 \%$ 3.0-3.8). Four-year decline in WAI/WAS further increased the risk. During the first four years of follow-up, the area under the curve (AUC) for WAI at cut-off point 27 was 0.66 (sensitivity $49.2 \%$ and specificity $82.9 \%$ ) and 0.64 for cut-off point 36 (sensitivity $84.2 \%$ and specificity $44.3 \%$ ). For WAS at cut-off point 5, the figures were AUC 0.63 (sensitivity $41.9 \%$ and specificity $85.0 \%$ ) and AUC 0.65 for cut-off point 7 (sensitivity $78.2 \%$ and specificity $52.7 \%$ ).

Conclusion The single-item WAS can be considered a reasonable alternative to the seven-item WAI in describing the risk of DP and as a prognostic tool.

Key terms disability retirement; early retirement; Finland; prognostic risk marker; prognostic tool; sensitivity; specificity; WAI; WAS; work ability score.

The work ability index (WAI) questionnaire was developed in the 1980s at the Finnish Institute of Occupational Health (FIOH) as a tool to measure work ability, to evaluate the effects of work ability promotion programs, and to screen individuals to identify the need for rehabilitation (1). Nowadays, WAI is commonly used worldwide for assessing work ability. WAI has also shown predictive value in the sense that a decreased WAI level increases the likelihood of premature retirement and death $(2,3,4)$. However, multi-item measures such as WAI have disadvantages in terms of implementation, interpretation, and cost (5). WAI has been criticized for its theoretical and practical complexity, and more simple ways to monitor work ability have been requested $(6,7)$.

The first item on the WAI questionnaire, known as the work ability score (WAS), is the self-assessment of current overall work ability level (range $0-10$ ) in comparison to lifetime best. A relatively strong agreement between WAI and WAS has been reported $(8,9)$. Further, convergent validity between these tools has been shown, ie, work ability measured using WAS has been associated with the same individual and occupational factors as WAI-based work ability (7). Among women on long-

1 Finnish Institute of Occupational Health, Helsinki, Finland.

2 School of Health Sciences, University of Tampere, Tampere, Finland.

3 Department of Mathematics and Statistics, University of Helsinki, Helsinki, Finland.

Correspondence to: Päivi Leino-Arjas, Finnish Institute of Occupational Health, PO Box 40, FI-00251 Helsinki, Finland. [E-mail: paivi. leino-arjas@ttl.fi] 
term sick leave, both WAI and WAS strongly predicted the future amount of sick leave (6). Health problems were clearly related to lower and decreasing WAS in a longitudinal study of middle-aged Dutch employees (10).

Recently, Roelen et al (11) compared the single-item WAS with the multi-item WAI to identify male construction workers at risk of disability pension (DP), and found that despite being associated with the outcome, WAS poorly differentiated high- and low-risk individuals. However, their findings were based on a rather short follow-up time and self-reported work status. More information is needed on WAI and WAS as antecedents of disability retirement in a wider range of occupations and among both genders. Furthermore, information is lacking on the importance of changes over time in WAI or WAS in relation to incident DP.

Here, we investigated among municipal employees the seven-item WAI and the single-item WAS, and their subsequent change over four years, as determinants of DP using register-based data on the outcome. We also examined whether the relationships varied according to gender or the type of work performed, ie, when the main demands of the job were physical, mental or both physical and mental. We also assessed the ability of the WAI and WAS to discriminate between individuals in predicting DP. The baseline data were originally used in the development of the WAI and its categorization (12).

\section{Methods}

\section{Study sample}

Data were derived from the Finnish Longitudinal Study of Ageing Municipal Employees (FLAME) (13). For the study, the 112 largest occupational groups in the municipal sector from the largest municipalities in Finland were chosen after negotiations with the Municipal Pension Fund and employee and employer organizations. Subjects with $\geq 5$ years work history in their current occupation were targeted. Data collection began in 1981 when the subjects were aged $44-58$ years and follow-ups were carried out in 1985, 1992, 1997 and 2009. The baseline sample comprised 6257 employees ( $44.7 \%$ men). The response rate was $85.2 \%$. Of these, $5556(88.8 \%)$ took part also in the 4-year follow-up. Data were gathered through questionnaires, clinical measurements and national registers. Here we used the questionnaire responses of the two first measurements linked with information from the national pension and mortality registers. The linkages were made using each person's unique identification code.

The ethics committee of the Finnish Institute of Occupational Health approved the study. Ethical clear- ance for the register linkages was obtained from the national Data Protection Ombudsman.

\section{Outcome variable}

The outcome variable comprised all incident DP among the cohort. Data on DP were obtained from the national registers of the Finnish Centre for Pensions, which provides complete information of all retirement events. Mortality data were extracted from the Finnish National Population Register. Information on pensions and mortality was linked to the data using the participant's identification number.

Illness-based DP included full ( $\mathrm{N}=1478)$ and parttime $(\mathrm{N}=1) \mathrm{DP}$, individual early retirement pensions $(\mathrm{N}=837)$ and war veterans' early retirement pensions $(\mathrm{N}=181)$. Individual early retirement pension was a special type of DP that was available from the late 1980s until 2005 to employees born before 1944 who had a long working career and a substantially decreased work capacity due to impaired health, but the medical eligibility criteria were less strict than for the ordinary DP. Early retirement pension for war veterans was an illness-based pension that came into force in 1982 and was available to 58-64-year-old men and women recognized for their service during 1939-1945.

The study sample was followed for DP awards, oldage pension awards, and death from 1 January 1981 to 31 December 2009.

\section{Explanatory variables}

Work ability index (WAI). The validity and reliability of WAI have been tested using clinical data and correlation analyses $(8,14,15,16,17)$. The theoretical framework of work ability comes from Rutenfranz's (18) stressstrain concept, and work ability is defined as the individual's capacity to manage occupational demands (13).

WAI measures seven aspects: (i) current work ability compared with lifetime best, (ii) work ability in relation to the physical and mental demands of the job, (iii) current number of illnesses or injuries diagnosed by a doctor, (iv) estimated work impairment due to those illnesses or injuries, (v) sick leave taken in the past 12 months, (vi) the worker's own prognosis of his or her work ability in two years' time, and (vii) the worker's mental resources to accomplish his or her job (table 1). WAI is derived as the sum of the ratings on these seven items. The range of the summative index is 7-49. Originally (12), the cut-off points for the levels of work ability were based on the $15^{\text {th }}$ percentile, median, and $85^{\text {th }}$ percentile of the distribution of the index in the total population at baseline: (i) poor (7-27), (ii) moderate (28-36), (iii) good (37-43), and (iv) excellent (44-49). For the analyses here, we combined good and excellent work ability into one category. 
Table 1. The work ability index [Tuomi et al (12)].

\begin{tabular}{|c|c|c|c|}
\hline Item & $\begin{array}{l}\text { Questions } \\
\text { (N) }\end{array}$ & $\begin{array}{l}\text { Scoring of } \\
\text { responses }\end{array}$ & Explanation \\
\hline $\begin{array}{l}1 \text { : Current work } \\
\text { ability compared } \\
\text { with lifetime best }\end{array}$ & 1 & $0-10$ & $\begin{array}{l}0=\text { completely unable to work } \\
10=\text { work ability at its best }\end{array}$ \\
\hline $\begin{array}{l}\text { 2: Work ability } \\
\text { in relation to } \\
\text { demands of job }\end{array}$ & 2 & $2-10$ & $\begin{array}{l}2=\text { very poor } \\
10=\text { very good }\end{array}$ \\
\hline $\begin{array}{l}\text { 3: Number of } \\
\text { current diseases } \\
\text { diagnosed by } \\
\text { physician }\end{array}$ & $\begin{array}{l}1 \text { (list } \\
\text { of } 51 \\
\text { dis- } \\
\text { eases) }\end{array}$ & $1-7$ & $\begin{array}{l}1=5 \text { or more diseases } \\
2=4 \text { diseases } \\
3=3 \text { diseases } \\
4=2 \text { diseases } \\
5=1 \text { disease } \\
7=\text { no disease }\end{array}$ \\
\hline $\begin{array}{l}\text { 4: Estimated work } \\
\text { impairment due } \\
\text { to diseases }\end{array}$ & 1 & $1-6$ & $\begin{array}{l}1=\text { entirely unable to work } \\
6=\text { no impairment }\end{array}$ \\
\hline $\begin{array}{l}\text { 5: Sick leave } \\
\text { during past year } \\
\text { (12 months) }\end{array}$ & 1 & $1-5$ & $\begin{array}{l}1=100 \text { days or more } \\
2=25-99 \text { days } \\
3=10-24 \text { days } \\
4=1-9 \text { days } \\
5=0 \text { days }\end{array}$ \\
\hline $\begin{array}{l}\text { 6: Own prognosis } \\
\text { of work ability two } \\
\text { years from now }\end{array}$ & 1 & $1,4,7$ & $\begin{array}{l}1=\text { unlikely } \\
4=\text { not certain } \\
7=\text { relatively certain }\end{array}$ \\
\hline $\begin{array}{l}\text { 7: Mental resources } \\
\text { (both at work and } \\
\text { during leisure time) }\end{array}$ & 3 & $1-4$ & $\begin{array}{l}1=\text { very poor } \\
4=\text { very good }\end{array}$ \\
\hline
\end{tabular}

In addition, we calculated the 4-year change in WAI by subtracting the 1981 score from that of 1985 . We categorized the differences into three classes: (i) WAIbased work ability strongly deteriorated (WAI decreased by $\geq 9$ points, ie, below the lowest $15^{\text {th }}$ percentile); (ii) WAI-based work ability slightly deteriorated (WAI decreased by $1-8$ points); (iii) no change or WAI-based work ability improved (WAI increased by $\geq 1$ point).

In receiver operating characteristic (ROC) analyses the index was used as a continuous variable.

Work ability score (WAS). The first item of WAI measures present work ability compared to lifetime best with the question: "Assume that your work ability at its best has a value of 10 points. What score would you give your current work ability?" This question has been found to have the highest discriminating power over the entire index (8). WAS ranges from 0 (completely unable to work) to 10 (work ability at its best) and we used the classification of WAS which has been found to best correspond to that of WAI (19): poor (0-5 points), moderate (6-7), good (8-9), excellent (10). We combined good and excellent work ability and used three categories in the analyses.

We also calculated the 4-year change in WAS by subtracting the score in 1981 from the score in 1985 and classified the differences as follows: (i) WAS-based work ability strongly deteriorated (WAS decreased by $\geq 3$ points, ie, below the lowest $15^{\text {th }}$ percentile); (ii) WASbased work ability slightly deteriorated (WAS decreased by 1 or 2 points); (iii) no change or WAS-based work ability improved (WAS increased by $\geq 1$ point).
In ROC analyses, the index was used as a continuous variable.

Job content categories. In order to classify the range of municipal occupations covering the health care, social welfare, technical, administrative sector, and office work into relatively homogeneous groups, the ergonomic job analysis method "Arbeitswissenschaftliche Erhebungsverfahren zur Tätigkeitsanalyse" (AET) was used (20). Detailed interviews and observations of physical, psychosocial and mental characteristics (altogether 216 items) of 88 jobs were carried out at the workplaces of 133 subjects by researchers trained for the purpose (21). The analyzed items (coded $0-5$ according to their duration or frequency) included the work system (work objects, equipment and environment), work tasks, and physical and mental work demands. Based on this information, altogether 13 profile groups emerged in cluster analysis. These were further classified as physical, mental, or mixed (physical-mental) type of work. Job content was considered as mainly physical in auxiliary and installation work among men and in auxiliary and home-care work among women, and mental in administrative work, technical supervision, physician's work, and teaching among men, and in office work, administrative work, physician's work, and teaching among women. The mixed physicalmental category covered transport, dental, nursing, and dump work among men, and kitchen supervision, dental, and nursing work among women. (22).

The job analysis was repeated in 1993 and, according to the results, there were no larger changes in work demands in the occupations between 1981 and 1993 (23). Also, changes of occupation were fairly uncommon among the subjects. For example, $88 \%$ of those active workers who responded to the follow-up survey in 1992 had worked at the same job for at least the past 15 years $(24)$.

Other covariates. We used age and basic education level as covariates. Age was categorized into four groups: 44-47, 48-50, 51-54, and 55-58 years. Basic education was categorized as (i) elementary school not completed, (ii) elementary school, (iii) lower secondary school, and (iv) upper secondary school.

\section{Statistical analysis}

We calculated hazard ratios (HR) of DP and their 95\% confidence intervals $(95 \% \mathrm{CI})$ using Cox proportional hazards regression. First, we analyzed HR of DP connected with the WAI and WAS at baseline, during the follow-up from 1 January 1981 to 31 December 2009. Second, we studied the effects of the 4-year changes in WAI and WAS in relation to DP from 1 January 1986 onwards, including also the baseline value of the indi- 
cator in the model as an independent variable. In both types of analyses, the follow-up ended with the award of a DP or other pension, or death, whichever came first. Independent censoring was assumed. As covariates we included age, gender, basic education and job content. Additionally, analyses stratified by gender, and by gender and job content, were carried out, to examine possible effect modification by these. Spearman rank correlation was used to analyze the association between baseline WAI and baseline WAS.

To obtain information on the discriminative ability of the WAI and WAS regarding future disability retirement, we performed ROC analyses to assess area under the curve (AUC) values and the sensitivity and specificity at the used cut-off points. Also the optimal cut-off point based on the Youden index (25) was determined. The $95 \%$ CI for the AUC values were obtained by the Mann-Whitney U statistic. These analyses were made for disability retirement during 1981-1985. The interval was chosen because we wanted to have a sufficiently large number of DP for the analysis while restricting the number of deaths and old age retirement.

There were relatively few missing data. The largest proportion (16\%) was found in the multi-item WAI due to one or more incompletely filled questionnaire items.
We restricted the analyses to those with complete information for calculating the WAI $(\mathrm{M}=5251)$.

The statistical analyses were conducted using SPSS Statistics 21.0 (IBM Corp, Armonk, NY, USA).

\section{Results}

The baseline characteristics of the study population are shown in table 2. The Spearman correlation coefficient for the association between baseline WAI and baseline WAS was 0.80 in the total sample, 0.82 among men, and 0.79 among women. On average, the change in WAS between 1981 and 1985 was -0.9 in the total sample, -1.0 points among men, and -0.8 points among women. The mean 4-year change in WAI was -2.8 points among both men and women.

Over the follow-up, 2057 subjects (1098 men and 959 women) were granted DP, 3194 (1196 men and 1998 women) retired on old-age pension or other non-illnessbased pension and 1612 (974 men and 638 women) died before receiving any type of pension.

Table 3 presents the HR related to baseline WAI and the 4-year change in WAI. Overall, covariate addition

Table 2. Characteristics of the study population at baseline in 1981. [SD=standard deviation.]

\begin{tabular}{|c|c|c|c|c|c|c|c|c|c|}
\hline & \multicolumn{3}{|c|}{ All $(\mathrm{N}=5251)$} & \multicolumn{3}{|c|}{ Men $(\mathrm{N}=2294)$} & \multicolumn{3}{|c|}{ Women $(\mathrm{N}=2957)$} \\
\hline & Mean & SD & $\%$ & Mean & SD & $\%$ & Mean & SD & $\%$ \\
\hline Work ability index (WAI) & 35.9 & 7.6 & & 35.5 & 7.9 & & 36.3 & 7.3 & \\
\hline \multicolumn{10}{|l|}{ WAI-based work ability } \\
\hline Poor (7-27) & & & 13.9 & & & 15.8 & & & 12.5 \\
\hline Moderate (28-36) & & & 33.3 & & & 33.9 & & & 32.9 \\
\hline Good/excellent (37-49) & & & 52.8 & & & 50.3 & & & 54.6 \\
\hline Work ability score (WAS) & 7.4 & 1.9 & & 7.2 & 1.9 & & 7.6 & 1.8 & \\
\hline \multicolumn{10}{|l|}{ WAS-based work ability } \\
\hline Poor $(0-5)$ & & & 14.2 & & & 16.2 & & & 12.5 \\
\hline Moderate $(6-7)$ & & & 29.9 & & & 34.8 & & & 25.8 \\
\hline Good/excellent (8-10) & & & 56.0 & & & 49.0 & & & 61.7 \\
\hline \multicolumn{10}{|l|}{ Basic education } \\
\hline Elementary school not completed & & & 19.5 & & & 25.9 & & & 14.5 \\
\hline Elementary school & & & 52.4 & & & 57.8 & & & 48.3 \\
\hline Lower secondary school & & & 17.5 & & & 8.2 & & & 24.8 \\
\hline Upper secondary school & & & 10.5 & & & 8.1 & & & 12.4 \\
\hline \multicolumn{10}{|l|}{ Professional education } \\
\hline No vocational training & & & 30.4 & & & 43.4 & & & 20.5 \\
\hline $\begin{array}{l}\text { Lower vocational school or vocational } \\
\text { course }\end{array}$ & & & 63.0 & & & 48.9 & & & 73.7 \\
\hline $\begin{array}{l}\text { Higher vocational school (polytechnic) } \\
\text { or university }\end{array}$ & & & 6.6 & & & 7.7 & & & 5.8 \\
\hline Age in years & 50.4 & 3.6 & & 50.4 & 3.6 & & 50.3 & 3.6 & \\
\hline \multicolumn{10}{|l|}{ Age group (years) } \\
\hline $44-47$ & & & 26.9 & & & 25.9 & & & 27.7 \\
\hline $48-50$ & & & 26.5 & & & 27.3 & & & 25.8 \\
\hline $51-54$ & & & 30.1 & & & 30.3 & & & 30.0 \\
\hline $55-58$ & & & 16.5 & & & 16.5 & & & 16.5 \\
\hline \multicolumn{10}{|l|}{ Job content } \\
\hline Physical & & & 39.9 & & & 46.8 & & & 34.5 \\
\hline Mental & & & 29.4 & & & 28.4 & & & 30.1 \\
\hline Physical-mental (mixed) & & & 30.7 & & & 24.8 & & & 35.4 \\
\hline
\end{tabular}


had little effect on the estimates. In the total sample, the HR related to poor WAI-based work ability at baseline was $5.40(95 \%$ CI 4.81-6.07) when adjusted for age and gender and 4.96 (95\% CI 4.40-5.60) when further adjusted for basic education and job content. The HR were higher among women than men. In model 3 which included the baseline WAI, the 4-year change in WAI, age, basic education, and job content as independent variables - a strong decline in WAI was associated with DP [HR 3.83 (95\% CI 2.97-4.93) among men and HR 3.40 (95\% CI 2.62-4.40) among women].

Both poor and moderate WAS-based work ability were associated with DP (table 4) but the HR were lower than those related to WAI. Between men and women, the differences in HR related to low baseline WAS were less pronounced than those related to low WAI. In model 3 - which included the baseline WAS, the 4-year change in WAS, age, basic education, and job content as independent variables - a strong decline in WAS was associated with DP [HR 2.23 (95\% CI 1.78-2.79) among men and HR 2.54 (95\% CI 2.03-3.19) among women].

In the job content-stratified analyses conducted among men (table 5), the HR related to work ability measures varied fairly little across the strata. A slight decline in either WAI- or WAS-based work ability was not associated with subsequent DP among men in mixed type of work, but otherwise, all associations of work ability measures with DP were statistically significant. The HR associated with moderate and poor baseline WAI-based work ability were somewhat increased by the inclusion of longitudinal data on WAI in the model (model 2 versus model 3). The HR related to moderate and poor baseline WAS-based work ability were essen- tially similar in models 2 and 3.

Among women (table 6), the HR related to poor WAIbased work ability at baseline varied 5.78-9.09 in the basic model and 6.54-8.01 in the further adjusted model and were thus higher than those for men. The highest HR were observed among women with mixed job demands. The HR related to poor WAS-based work ability [3.37 (95\% CI 2.71-4.19) in physically demanding jobs; 3.53 (95\% CI 2.49-4.98) in mentally demanding jobs; 5.24 (95\% CI 3.80-7.22) in mixed type of work] were lower than those related to WAI and were further decreased by the inclusion of the change in WAS in the analysis.

The AUC value for the baseline WAI predicting disability retirement during $1981-1985$ was $0.68(95 \% \mathrm{CI}$ $0.64-0.72$ ) among men and 0.79 (95\% CI $0.75-0.82)$ among women. The AUC value for the single-item WAS in corresponding analyses was 0.65 (95\% CI $0.61-0.69)$ for men and $0.76(95 \%$ CI $0.72-0.80)$ for women. Among men, the optimal cut-off point of WAI - based on the Youden index - was 24.0 (sensitivity $58.5 \%$ and specificity $67.1 \%$ ); among women, it was 23.9 (sensitivity $75.3 \%$ and specificity $71.3 \%$ ). For the WAS, the optimal cut-off point among men was 4.5 (sensitivity $56.7 \%$ and specificity $68.7 \%$ ); in women, it was 4.6 (sensitivity $58.7 \%$ and specificity $81.2 \%$ ).

At the cut-off point of poor WAI (27) in the total material, the AUC was 0.66 (95\% CI 0.6-0.69), sensitivity and specificity were $49.2 \%$ and $82.9 \%$, respectively. At the cut-off point of moderate WAI (36) the respective figures were AUC 0.64 (95\% CI 0.62-0.67), sensitivity $84.2 \%$ and specificity $44.3 \%$. For the WAS, at cut-off point 5, these were AUC 0.63 (95\% CI 0.62-0.66), sensitivity $41.9 \%$ and specificity $85.0 \%$, and for cut-

Table 3. Work ability index (WAI) at baseline in relation to disability pension (DP) awards during follow-up 1981-2009 (models 1 and 2) among municipal employees; WAI at baseline and its change during 1981-1985 in relation to DP awards during 1986-2009 (model 3). Cox regression analysis. [HR=hazard ratio; $95 \% \mathrm{Cl}=95 \%$ confidence intervals.]

\begin{tabular}{|c|c|c|c|c|c|c|c|c|c|c|c|}
\hline & \multirow{3}{*}{$\begin{array}{c}\begin{array}{c}\text { Disability } \\
\text { pension } \\
\text { awards }\end{array} \\
\mathrm{N}\end{array}$} & \multicolumn{5}{|c|}{ WAI-based work ability at baseline } & \multicolumn{5}{|c|}{ Change in WAI-based work ability } \\
\hline & & \multirow{2}{*}{$\frac{\begin{array}{c}\text { Good/ } \\
\text { excellent }\end{array}}{\mathrm{HR}}$} & \multicolumn{2}{|c|}{ Moderate } & \multicolumn{2}{|c|}{ Poor } & \multirow{2}{*}{$\begin{array}{c}\begin{array}{c}\text { No change/ } \\
\text { improved }\end{array} \\
\mathrm{HR} \\
\end{array}$} & \multicolumn{2}{|c|}{$\begin{array}{c}\text { Slightly } \\
\text { deteriorated }\end{array}$} & \multicolumn{2}{|c|}{$\begin{array}{c}\text { Strongly } \\
\text { deteriorated }\end{array}$} \\
\hline & & & $\mathrm{HR}$ & $95 \% \mathrm{Cl}$ & $\mathrm{HR}$ & $95 \% \mathrm{Cl}$ & & $\mathrm{HR}$ & $95 \% \mathrm{Cl}$ & $\mathrm{HR}$ & $95 \% \mathrm{Cl}$ \\
\hline \multicolumn{12}{|l|}{ All } \\
\hline Model $1^{\text {a }}$ & 2057 & 1.00 & 2.14 & $1.94-2.36$ & 5.40 & $4.81-6.07$ & . & . & .. & & .. \\
\hline Model $2 \mathrm{~b}$ & 2048 & 1.00 & 1.98 & $1.78-2.19$ & 4.96 & $4.40-5.60$ & & & .. & & .. \\
\hline Model $3^{c}$ & 1232 & 1.00 & 2.45 & $2.15-2.79$ & 5.50 & $4.52-6.69$ & 1.00 & 1.58 & $1.37-1.81$ & 3.69 & $3.08-4.41$ \\
\hline \multicolumn{12}{|l|}{ Men } \\
\hline Model $1^{a}$ & 1098 & 1.00 & 1.94 & $1.69-2.23$ & 4.30 & $3.67-5.03$ & . & . & .. & & .. \\
\hline Model $2^{b}$ & 1093 & 1.00 & 1.81 & $1.57-2.09$ & 4.07 & $3.45-4.79$ & & & .. & & .. \\
\hline Model $3^{c}$ & 614 & 1.00 & 2.13 & $1.77-2.56$ & 4.49 & $3.41-5.91$ & 1.00 & 1.58 & $1.30-1.93$ & 3.83 & $2.97-4.93$ \\
\hline \multicolumn{12}{|l|}{ Women } \\
\hline Model 1 a & 959 & 1.00 & 2.36 & $2.04-2.73$ & 7.45 & $6.28-8.85$ & . & . & .. & & .. \\
\hline Model $2 \mathrm{~b}$ & 955 & 1.00 & 2.20 & $1.89-2.56$ & 6.67 & $5.57-7.98$ & & & .. & & .. \\
\hline Model $3^{c}$ & 618 & 1.00 & 2.77 & $2.31-3.32$ & 7.08 & $5.34-9.40$ & 1.00 & 1.58 & $1.30-1.92$ & 3.40 & $2.62-4.40$ \\
\hline
\end{tabular}

a Baseline WAI, age, and gender (unless gender-stratified) included as covariates.

${ }^{b}$ Baseline WAI, age, gender (unless gender-stratified), basic education level, and job content included as covariates.

'Baseline WAl, change in WAl from 1981 to 1985, age, gender (unless gender-stratified), basic education level, and job content included as covariates. The follow-up of disability pension awards started in 1986. 
Table 4. Single-item work ability score (WAS) in relation to disability pension (DP) awards during follow-up 1981-2009 (models 1 and 2) among municipal employees; WAS at baseline and its change during 1981-1985 in relation to DP awards during 1986-2009 (model 3). Cox regression analysis. [HR=hazard ratios; $95 \% \mathrm{Cl}=95 \%$ confidence interval; NC=no change.]

\begin{tabular}{|c|c|c|c|c|c|c|c|c|c|c|c|}
\hline & \multirow{3}{*}{$\begin{array}{c}\begin{array}{c}\text { Disability } \\
\text { pension } \\
\text { awards }\end{array} \\
\mathrm{N}\end{array}$} & \multicolumn{5}{|c|}{ WAS-based work ability at baseline } & \multicolumn{5}{|c|}{ Change in WAS-based work ability } \\
\hline & & \multirow{2}{*}{$\frac{\begin{array}{c}\mathrm{Good} / \\
\text { excellent }\end{array}}{\mathrm{HR}}$} & \multicolumn{2}{|c|}{ Moderate } & \multicolumn{2}{|c|}{ Poor } & \multirow{2}{*}{$\begin{array}{c}\begin{array}{c}\mathrm{NC} / \\
\text { improved }\end{array} \\
\mathrm{HR}\end{array}$} & \multicolumn{2}{|c|}{$\begin{array}{c}\text { Slightly } \\
\text { deteriorated }\end{array}$} & \multicolumn{2}{|c|}{$\begin{array}{c}\text { Strongly } \\
\text { deteriorated }\end{array}$} \\
\hline & & & $\mathrm{HR}$ & $95 \% \mathrm{Cl}$ & $\mathrm{HR}$ & $95 \% \mathrm{Cl}$ & & HR & $95 \% \mathrm{Cl}$ & $\mathrm{HR}$ & $95 \% \mathrm{Cl}$ \\
\hline \multicolumn{12}{|l|}{ All } \\
\hline Model 1 a & 2057 & 1.00 & 1.88 & $1.72-2.07$ & 3.70 & $3.33-4.11$ & . & . & .. & . & .. \\
\hline Model $2^{b}$ & 2048 & 1.00 & 1.78 & $1.62-1.95$ & 3.38 & $3.03-3.77$ & . & . & .. & . & .. \\
\hline Model $3^{c}$ & 1232 & 1.00 & 1.87 & $1.67-2.10$ & 2.66 & $2.27-3.12$ & 1.00 & 1.32 & $1.18-1.48$ & 2.37 & $2.02-2.78$ \\
\hline \multicolumn{12}{|l|}{ Men } \\
\hline Model $1^{\text {a }}$ & 1098 & 1.00 & 1.79 & $1.58-2.02$ & 3.25 & $2.81-3.75$ & . & . & .. & . & .. \\
\hline Model 2 b & 1093 & 1.00 & 1.72 & $1.51-1.95$ & 3.07 & $2.64-3.57$ & & & .. & . & .. \\
\hline Model $3^{c}$ & 614 & 1.00 & 1.80 & $1.54-2.11$ & 2.52 & $2.02-3.14$ & 1.00 & 1.34 & $1.14-1.57$ & 2.23 & $1.78-2.79$ \\
\hline \multicolumn{12}{|l|}{ Women } \\
\hline Model 1 a & 959 & 1.00 & 1.96 & $1.71-2.26$ & 4.24 & $3.63-4.95$ & . & . & .. & . & .. \\
\hline Model 2 b & 955 & 1.00 & 1.81 & $1.57-2.09$ & 3.72 & $3.17-4.37$ & & & .. & . & .. \\
\hline Model $3^{c}$ & 618 & 1.00 & 1.94 & $1.64-2.30$ & 2.84 & $2.26-3.58$ & 1.00 & 1.31 & $1.11-1.55$ & 2.54 & $2.03-3.19$ \\
\hline
\end{tabular}

off point 7, AUC $0.65(95 \%$ CI $0.63-0.68)$, sensitivity $78.2 \%$ and specificity $52.7 \%$.

\section{Discussion}

Using register data on retirement events and mortality covering years 1981-2009, we found that both WAI and WAS predicted DP among Finnish municipal employees, WAI somewhat better. WAI-based poor work ability at baseline was associated with a higher risk of DP for women than men. Job content-stratified analysis revealed it was particularly strong among women in mixed-demand occupations, such as nursing, dental work, and kitchen supervision. In addition, a strong decline in WAI or WAS over the first four years of follow-up was clearly associated with the risk of DP in models that also included the baseline level of WAI or WAS: HR connected with the change ranging from 2.0-4.6. Based on AUC values, the ability of the WAI and WAS in discriminating subjects with future disability retirement during the first four years of follow-up was adequate among women (WAI 0.79, WAS 0.76 ) and moderate among men (WAI 0.68, WAS 0.65 ). The result in men is in line with previous findings among construction workers (11), with the difference that the latter had a shorter follow-up of a younger sample. The optimal cutoff points of WAI and WAS were very similar for both genders (WAI: men 24.0, women 23.9; WAS: men 4.5, women 4.6), and the associated sensitivity and specificity were adequate, being higher among women. When we further analyzed the disability pensions awarded during 1986-1990 and included also the 4-year change in the work ability score during 1981-1985, in addition to the baseline score as an independent variable, the AUC values for the model increased and were satisfactory also for the WAS (WAI: men 0.73, women 0.80; WAS: men 0.71 , women 0.79 ).

Not all the participants who rated their WAS as high scored the highest WAI points, but the correlation of the measures was however high. It is possible that some participants had never regarded their work ability as good (low WAI) and estimated their current work ability to be close to their lifetime best (high WAS). This reflects the different content of these work ability measures. WAS takes into consideration previous abilities, and although it is an integral part of the WAI questionnaire, WAI is generally more focused on the current level of work ability and includes also an estimation of future work ability. Moreover, WAI covers recent sickness absences and physician-diagnosed illnesses that belong intrinsically to the process leading to a DP.

Our findings concerning the significance of WAI in relation to disability retirement are in line with several previous reports $(3,4,26,27)$. Among the studies on both WAI and WAS predating disability retirement, ours is the first to use longitudinal data on work ability. However, Ahlstrom et al (6) used 6-month changes in WAI and WAS and found them comparable to WAI and WAS measured at one time point, in relation to sick leave and several other health-related outcomes. Furthermore, previous studies have not taken into account the effect of the nature of the work on the associations.

The strengths of our analysis were the use of data on disability retirement drawn from national registers, the long-term follow-up, and the inclusion of the nature of work in the analyses (as a covariate and a possible modi- 
Table 5. Work Ability Index (WAI) and the single-item Work Ability Score (WAS) at baseline in relation to disability pension (DP) awards during 1981-2009 among men. Cox regression analysis stratified by job content (physical, mental or mixed). Hazard ratios (HR) and their $95 \%$ confidence intervals $(\mathrm{Cl})$.

\begin{tabular}{|c|c|c|c|c|c|c|c|c|c|c|c|c|}
\hline & \multicolumn{4}{|c|}{ Physical jobs } & \multicolumn{4}{|c|}{ Mental jobs } & \multicolumn{4}{|c|}{ Mixed jobs } \\
\hline & \multicolumn{2}{|c|}{ Model 1} & \multicolumn{2}{|c|}{ Model 2} & \multicolumn{2}{|c|}{ Model 1} & \multicolumn{2}{|c|}{ Model 2} & \multicolumn{2}{|c|}{ Model 1} & \multicolumn{2}{|c|}{ Model 2} \\
\hline & $\mathrm{HR}$ & $95 \% \mathrm{Cl}$ & $\mathrm{HR}$ & $95 \% \mathrm{Cl}$ & $\mathrm{HR}$ & $95 \% \mathrm{Cl}$ & $\mathrm{HR}$ & $95 \% \mathrm{Cl}$ & $\mathrm{HR}$ & $95 \% \mathrm{Cl}$ & $\mathrm{HR}$ & $95 \% \mathrm{Cl}$ \\
\hline \multicolumn{13}{|l|}{ WAI at baseline } \\
\hline Good/excellent & $1.00^{\mathrm{a}}$ & .. & $1.00^{b}$ & .. & $1.00^{a}$ & & $1.00^{b}$ & & $1.00^{\mathrm{a}}$ & & $1.00^{b}$ & .. \\
\hline Moderate & $1.63^{a}$ & $1.34-1.98$ & $1.86^{b}$ & $1.44-2.41$ & $2.81^{a}$ & $2.16-3.67$ & $4.07^{b}$ & $2.80-5.93$ & $1.62^{\mathrm{a}}$ & $1.17-2.25$ & $2.66^{b}$ & $1.70-4.18$ \\
\hline Poor & $4.02^{a}$ & $3.23-5.01$ & $4.48^{b}$ & $3.02-6.63$ & $5.66^{a}$ & $4.05-7.91$ & $6.55^{b}$ & $3.90-11.01$ & $3.82^{\mathrm{a}}$ & $2.69-5.42$ & $5.29^{b}$ & $2.83-9.86$ \\
\hline \multicolumn{13}{|l|}{ Change in WAI } \\
\hline No change/improved & . & .. & $1.00^{b}$ & & . & .. & $1.00^{b}$ & & . & .. & $1.00^{b}$ & \\
\hline Slightly deteriorated & . & .. & $1.66^{b}$ & $1.25-2.20$ & . & .. & $1.79^{b}$ & $1.22-2.63$ & . & .. & $1.54^{b}$ & $0.97-2.46$ \\
\hline Strongly deteriorated & . & .. & $4.33^{b}$ & $2.98-6.30$ & . & .. & $4.00^{b}$ & $2.54-6.31$ & . & .. & $3.11^{b}$ & $1.63-5.95$ \\
\hline \multicolumn{13}{|l|}{ WAS at baseline } \\
\hline Good/excellent & $1.00^{c}$ & .. & $1.00^{d}$ & .. & $1.00^{c}$ & .. & $1.00^{d}$ & & $1.00^{c}$ &.. & $1.00^{d}$ & \\
\hline Moderate & $1.60^{c}$ & $1.35-1.91$ & $1.70^{d}$ & $1.37-2.11$ & $2.17^{c}$ & $1.71-2.75$ & $2.22^{d}$ & $1.67-2.96$ & $1.51^{\mathrm{c}}$ & $1.13-2.02$ & $1.84^{\mathrm{d}}$ & $1.25-2.71$ \\
\hline Poor & $2.95^{c}$ & $2.41-3.60$ & $2.51^{d}$ & $1.85-3.41$ & $4.11^{\mathrm{c}}$ & $2.90-5.83$ & $4.73^{d}$ & $2.84-7.89$ & $2.83^{c}$ & $2.11-3.81$ & $3.05^{d}$ & $1.92-4.86$ \\
\hline \multicolumn{13}{|l|}{ Change in WAS } \\
\hline No change/improved & . & .. & $1.00^{d}$ & .. & . & .. & $1.00^{d}$ & .. & . & .. & $1.00^{d}$ & .. \\
\hline Slightly deteriorated & . & .. & $1.34^{d}$ & $1.07-1.67$ & . & .. & $1.54^{d}$ & $1.16-2.04$ & . & .. & $1.42^{d}$ & $0.95-2.14$ \\
\hline Strongly deteriorated & & .. & $2.54^{\mathrm{d}}$ & $1.85-3.48$ & & .. & $3.58^{d}$ & $2.21-5.82$ & . & .. & $2.10^{d}$ & $1.31-3.36$ \\
\hline
\end{tabular}

a Baseline WAI and age included as covariates; number of DP awards=583 for physical, 303 for mental, and 212 for mixed-demand jobs.

b Baseline WAI, age, and change in WAI included as covariates; number of DP awards=310 for physical, 203 for mental, and 103 for mixed-demand jobs.

c Baseline WAS and age included as covariates; number of DP awards=704 for physical, 331 for mental, and 268 for mixed-demand jobs.

d Baseline WAS, age, and change in WAS included as covariates; number of DP awards=409 for physical, 235 for mental, and 147 for mixed-demand jobs.

Table 6. Work ability index (WAI) and the single-item work ability score (WAS) at baseline in relation to disability pension (DP) awards during 1981-2009 among women. Cox regression analysis stratified by job content (physical, mental or mixed). [HR=hazard ratio; $95 \% \mathrm{Cl}=$ $95 \%$ confidence intervals.]

\begin{tabular}{|c|c|c|c|c|c|c|c|c|c|c|c|c|}
\hline & \multicolumn{4}{|c|}{ Physical jobs } & \multicolumn{4}{|c|}{ Mental jobs } & \multicolumn{4}{|c|}{ Mixed jobs } \\
\hline & \multicolumn{2}{|c|}{ Model 1} & \multicolumn{2}{|c|}{ Model 2} & \multicolumn{2}{|c|}{ Model 1} & \multicolumn{2}{|c|}{ Model 2} & \multicolumn{2}{|c|}{ Model 1} & \multicolumn{2}{|c|}{ Model 2} \\
\hline & $\mathrm{HR}$ & $95 \% \mathrm{Cl}$ & $\mathrm{HR}$ & $95 \% \mathrm{Cl}$ & $\mathrm{HR}$ & $95 \% \mathrm{Cl}$ & HR & $95 \% \mathrm{Cl}$ & $\mathrm{HR}$ & $95 \% \mathrm{Cl}$ & HR & $95 \% \mathrm{Cl}$ \\
\hline \multicolumn{13}{|l|}{$\begin{array}{l}\text { WAI-based work ability } \\
\text { at baseline }\end{array}$} \\
\hline Good/excellent & $1.00 \mathrm{a}$ & .. & $1.00^{b}$ & .. & $1.00^{a}$ & & $1.00^{b}$ & & $1.00^{a}$ & .. & $1.00^{b}$ & . \\
\hline Moderate & 2.09 a & $1.66-2.64$ & $2.64^{b}$ & $1.98-3.52$ & $2.39^{a}$ & $1.83-3.13$ & $2.92^{b}$ & $2.12-4.01$ & $2.28^{\mathrm{a}}$ & $1.71-3.05$ & $2.65^{b}$ & $1.85-3.78$ \\
\hline Poor & $6.18^{a}$ & $4.80-7.96$ & $6.54 \mathrm{~b}$ & $4.39-9.73$ & $5.78^{a}$ & $3.90-8.56$ & $6.68^{b}$ & $3.61-12.37$ & $9.09 \mathrm{a}$ & $6.39-12.94$ & $8.01^{\mathrm{b}}$ & $4.55-14.10$ \\
\hline \multicolumn{13}{|l|}{$\begin{array}{l}\text { Change in WAI-based } \\
\text { work ability }\end{array}$} \\
\hline No change/improved & . & .. & $1.00^{b}$ & .. & . & .. & $1.00^{b}$ & & & .. & $1.00^{b}$ & .. \\
\hline Slightly deteriorated & . & .. & $1.61^{\mathrm{b}}$ & $1.19-2.18$ & . & .. & $1.67^{b}$ & $1.16-2.41$ & & .. & $1.27^{\mathrm{b}}$ & $0.88-1.85$ \\
\hline Strongly deteriorated & . & .. & $2.75^{b}$ & $1.85-4.10$ & . & .. & $3.73^{b}$ & $2.36-5.89$ & & .. & $3.75^{b}$ & $2.24-6.28$ \\
\hline $\begin{array}{l}\text { WAS-based work abil- } \\
\text { ity at baseline }\end{array}$ & & & & & & & & & & & & \\
\hline Good/excellent & $1.00^{c}$ & 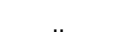 & $1.00^{d}$ & .. & $1.00^{c}$ & .. & $1.00^{d}$ & & $1.00^{c}$ & .. & $1.00^{d}$ & .. \\
\hline Moderate & $1.72^{c}$ & $1.40-2.10$ & $1.85^{d}$ & $1.44-2.37$ & $1.90^{c}$ & $1.44-2.51$ & $1.77^{\mathrm{d}}$ & $1.28-2.46$ & $1.95^{c}$ & $1.47-2.58$ & $2.54^{d}$ & $1.80-3.59$ \\
\hline Poor & $3.37^{c}$ & $2.71-4.19$ & $2.88^{d}$ & $2.09-3.98$ & $3.53^{c}$ & $2.49-4.98$ & $2.12^{d}$ & $1.30-3.46$ & $5.24^{c}$ & $3.80-7.22$ & $4.19^{d}$ & $2.57-6.82$ \\
\hline \multicolumn{13}{|l|}{$\begin{array}{l}\text { Change in WAS-based } \\
\text { work ability }\end{array}$} \\
\hline No change/improved & . & .. & $1.00^{d}$ & .. & . & .. & $1.00^{d}$ & & & .. & $1.00^{d}$ & .. \\
\hline Slightly deteriorated & . & .. & $1.23^{d}$ & $0.95-1.59$ & . & .. & $1.40^{d}$ & $1.05-1.88$ & & .. & $1.33^{d}$ & $0.96-1.84$ \\
\hline Strongly deteriorated & . & .. & $2.78^{d}$ & $2.01-3.84$ & . & .. & $2.39 \mathrm{~d}$ & $1.57-3.63$ & &.. & $2.97^{d}$ & $1.78-4.98$ \\
\hline
\end{tabular}

a Baseline WAI and age included as covariates; number of DP awards=452 for physical, 268 for mental, and 239 for mixed-demand jobs.

${ }^{b}$ Baseline WAI, age, and change in WAI included as covariates; number of DP awards=264 for physical, 205 for mental, and 153 for mixed-demand jobs.

c Baseline WAS and age included as covariates; number of DP awards=521 for physical, 285 for mental, and 268 for mixed-demand jobs.

d Baseline WAS, age, and change in WAS included as covariates; number of DP awards=331 for physical, 222 for mental, and 181 for mixed-demand jobs. 
fier). Previously, Roelen and colleagues (11) reported that among male construction workers after an average follow-up of 2.3 years, both WAI and WAS were associated with DP, but WAS poorly differentiated high- and low-risk individuals. As they used self-reported data on work status, social desirability bias may have affected their findings. According to Svedberg et al (28), who compared self-reports with national register data, the sensitivity for DP was only $70 \%$, ie, $30 \%$ of those with registered DP did not report them correctly. Register data are preferred in research because they are more accurate than self-reports and ensure complete data sets.

It should be noted that mortality was relatively high in our sample due to the fact that the sample consisted of middle-aged employees. It has been shown within this sample that the perceived work ability (WAS) was predictive of mortality (29). It can be assumed that the deceased persons had more severe morbidities compared to the survivors. Consequently, DP and death are competing outcomes in our study resulting in lower risk estimates of DP related to work ability.

The generalizability of our findings has some limitations. First, it should be noted that the data on work ability were collected in Finland in the early 1980s. Work, educational structure and the labor market have since changed considerably (30). The current demands of work are more often mental than physical and psychosocial workload has increased. Meanwhile, the work ability of the population has improved - thus, eg, poor work ability (WAI score 7-27) among municipal employees nowadays would be less prevalent. This improvement has been explained by the change in the population's educational level, especially that of women (19). Moreover, the physical health and functional capacity of Finns has improved (31), which might have affected work ability considering that health along with work is the main determinant of work ability. However, although subjective wellbeing at the population level has been found to be fairly stable (32), the share of mental healthrelated work disability has increased (33).

Second, work ability decreases with age even among the healthy. In the Finnish Health 2000 survey, nearly half of young adults perceived their work ability as excellent (WAI score 44-49), compared with $8 \%$ of 55-64 yearolds (19). In fact, it has been questioned whether the reference values of the WAI are suitable for the study of young employees (34). Further, owing to age-related differences in the causes of work disability, the results may not be generalizable to younger age groups.

Third, pension systems and work disability schemes (retirement age, eligibility criteria) vary from country to country, and legislative changes in social protection systems occur frequently, complicating the interpretation of pension statistics. In Finland, the prevalence of work disability has decreased since the 1980s in all age groups; however, the number of recipients of DP peaked between the mid-1980s and the mid-1990s $(33,19)$. This increase was due to so-called individual early retirement pension for people aged $\geq 55$ years, introduced in the public sectors in 1989 (private sectors 1986). Since its main eligibility criterion was a permanent reduction in working capacity due to an illness, we considered it equivalent to DP in the present study. Individual early retirement pension was abolished in 2005 . In addition, early retirement pension for war veterans was an illness-based pension that came into force in 1982 and caused a temporary increase in the number of older men retiring (35).

In our data, the proportion of missing data in the baseline WAI assessment due to incompletely filled questionnaires was $16 \%$. In another study, in which the WAI questionnaire was administered as part of a medical examination, the rates of complete and partial nonresponses were high: $44 \%$ and $28 \%$, respectively (7). The factors that influence participation in work ability assessment require further study, but it has been suggested that there could be an association between perceived health and participation, such that those with poor or declining health might not complete the questionnaire out of fear of being considered unfit for work (7). It has been shown that healthy individuals are more likely to participate in health surveys than those with poor health, a phenomenon called the "healthy volunteer effect" (36). Incomplete responses could be due to the difficulty of the questionnaire and a lack of understanding of its aim.

In conclusion, the single-item WAS can be considered a reasonable alternative to the 7-item WAI in describing the risk of future DP and as a prognostic tool. Longitudinal information on the development of WAI and WAS further increased the associated risk and discriminative ability of the measures. However, the generalization of the findings is limited by some factors, such as the characteristics of the study population (eg, age and occupation), national differences in retirement policies and the time point of the data collection.

\section{Acknowledgements}

The study was supported by a grant from the Social Insurance Institution, Finland.

We thank Ms Alice Lehtinen for editing the language of the manuscript.

\section{Ethics statement}

The ethics committee of the Finnish Institute of Occupational Health has approved the Finnish Longitudinal Study of Ageing Municipal Employees (FLAME). 


\section{Conflict of interest}

The authors declare no conflicts of interest.

\section{References}

1. Ilmarinen J. Work ability - a comprehensive concept for occupational health research and prevention. Scand J Work Environ Health. 2009;35:1-5. http://dx.doi.org/10.5271/ sjweh. 1304.

2. Tuomi K, Ilmarinen J, Seitsamo J, Huuhtanen P, Martikainen R, Nygård C-H, et al. Summary of the Finnish research project (1981-1992) to promote the health and work ability of aging workers. Scand J Work Environ Health. 1997;23 Suppl 1:S66-71.

3. Liira J, Matikainen P, Leino-Arjas P, Malmivaara A, Mutanen P, Rytkönen H, et al. Work ability of middle-aged Finnish construction workers - a follow-up study in 1991-1995. Int J Ind Ergon. 2000;25:477-81. http://dx.doi.org/10.1016/ S0169-8141(99)00032-3.

4. Sell L, Bultmann U, Rugulies R, Villadsen E, Faber A, Søgaard $\mathrm{K}$. Predicting long-term sickness absence and early retirement pension from self-reported work ability. Int Arch Occup Environ Health. 2009;82:113-8. http://dx.doi.org/10.1007/ s00420-009-0417-6.

5. Bowling A. Just one question: if one question works, why ask several? J Epidemiol Community Health. 2005;59:342-5. http://dx.doi.org/10.1136/jech.2004.021204.

6. Ahlstrom L, Grimpy-Ekman A, Hagberg M, Dellve L. The work ability index and single-item question: associations with sick leave, symptoms, and health - a prospective study of women on long-term sick leave. Scand J Work Environ Health. 2010;36:404-12. http://dx.doi.org/10.5271/sjweh.2917.

7. El Fassi M, Bocquet V, Majery N, Lair ML, Couffignal S, Mairiaux P. Work ability assessment in a worker population: comparison and determinants of Work Ability Index and Work Ability score. BMC Public Health. 2013;13:305. http://dx.doi. org/10.1186/1471-2458-13-305.

8. Radkiewicz P, Widerszal-Bazyl M. Psychometric properties of work ability index in the light of comparative survey study. Int Congr Ser. 2005;1280:304-9. http://dx.doi.org/10.1016/j. ics.2005.02.089.

9. Torgén M. Experiences of WAI in a random sample of the Swedish working population. Int Congr Ser. 2005;1280:32832. http://dx.doi.org/10.1016/j.ics.2005.01.016.

10. Leijten FRM, van den Heuvel SG, Fekke Ybema J, van der Beek AJ, Robroek SJW, Burdorf A. The influence of chronic health problems on work ability and productivity at work: a longitudinal study among older employees. Scand J Work Environ Health. 2014;40:473-82. http://dx.doi.org/10.5271/ sjweh.3444.

11. Roelen CA, van Rhenen W, Groothoff JW, van der Kink JJ, Twisk JW, Heymans MW. Work ability as prognostic risk marker of disability pension: single-item work ability score versus multi-item work ability index. Scand J Work Environ Health. 2014;40:428-31. http://dx.doi.org/10.5271/ sjweh.3428.

12. Tuomi K, Ilmarinen J, Jahkola A, Katajarinne L, Tulkki A. Work Ability Index. 2nd revised ed. Helsinki: Finnish Institute of Occupational Health; 1998.

13. Ilmarinen J, Tuomi $\mathrm{K}$, Eskelinen L, Nygård $\mathrm{CH}$, Huuhtanen P, Klockars M. Background and objectives of the Finnish research project on aging workers in municipal occupations. Scand J Work Environ Health. 1991;17 Suppl 1:S7-11.

14. Eskelinen L, Kohvakka A, Merisalo T, Hurri H, Wägar G. Relationship between the self-assessment and clinical assessment of health status and work ability. Scand J Work Environ Health. 1991;17 Suppl 1:S40-7.

15. Nygård CH, Eskelinen L, Suvanto S, Tuomi K, Ilmarinen J. Associations between functional capacity and work ability among elderly municipal employees. Scand J Work Environ Health. 1991;17 Suppl 1:S122-7.

16. Tuomi K, Huuhtanen P, Nykyri E, Ilmarinen J. Promotion of work ability, the quality of work and retirement. Occup Med (Lond). 2001;51:318-24. http://dx.doi.org/10.1093/ occmed/51.5.318.

17. de Zwart BCH, Frings-Dresen MHW, van Duivenbooden JC. Test-retest reliability of the Work Ability Index questionnaire. Occup Med (Lond). 2002;52:177-81. http://dx.doi. org/10.1093/occmed/52.4.177.

18. Rutenfranz J. Arbeitzmedizinische aspekte des stressproblems. In: Nitsh JR, editor. Theorien, untersuchungen, massnahmen. Bern: Verlag Hans Huber; 1981. p. 379-90.

19. Gould R, Ilmarinen J, Järvisalo J, Koskinen S, editors. Dimensions of work ability. Results of the Health 2000 Survey. Helsinki: Finnish Centre for Pensions, The Social Insurance Institution, National Public Health Institute, Finnish Institute of Occupational Health; 2008.

20. Rohmert W, Landau K. A new technique for job analysis. London and New York: Taylor and Francis; 1983.

21. Ilmarinen J, Suurnäkki T, Nygård CH, Landau K. Classification of municipal occupations. Scand J Work Environ Health. 1991;17 Suppl 1:S12-29.

22. Eskelinen L, Toikkanen J, Tuomi K, Mauno I, Nygård CH, Ilmarinen J. Symptoms of mental and physical stress in different categories of municipal work. Scand J Work Environ Health. 1991;17:82-6.

23. Nygård CH, Suurnäkki T, Peltomaa T, Ilmarinen J. Objectively assessed job demands among elderly municipal employees in 1981 and 1993. In: Kumashiro M, editor. The paths to productive aging. London: Taylor and Francis; 1995. p. 325-30.

24. Tuomi K, Ilmarinen J, Klockars M, Nygård C-H, Seitsamo J, Huuhtanen $\mathrm{P}$, et al. Finnish research project on aging workers 1981-1992. Scand J Work Environ Health. 1997;23 Suppl 1:S7-11.

25. Fluss R, Faraggi D, Reiser B. Youden Index and its associated cutoff point. Biom J. 2005;47:458-72. http://dx.doi. 
org/10.1002/bimj.200410135.

26. Alavinia SM, de Boer AG, van Duivenbooden JC, FringsDresen MH, Burdorf A. Determinants of work ability and is predictive value for disability. Occup Med (Lond). 2009;59:32-7. http://dx.doi.org/10.1093/occmed/kqn148.

27. Roelen CA, Heymans MW, Twisk JW, van der Klink JJ, Groothoff JW, van Rhenen W. Work Ability Index as tool to identify workers at risk of premature work exit. J Occup Rehabil. 2014b;24:747-54. http://dx.doi.org/10.1007/ s10926-014-9505-x.

28. Svedberg P, Ropponen A, Lichtenstein P, Alexanderson K. Are self-report of disability pension and long-term sickness absence accurate? Comparisons of self-reported interview data with national register data in a Swedish twin cohort. BMC Public Health. 2010;10:763. http://dx.doi.org/10.1186/14712458-10-763.

29. von Bonsdorff $\mathrm{MB}$, Seitsamo J, Ilmarinen J, Nygård $\mathrm{CH}$, von Bonsdorff ME, Rantanen T. Work ability in midlife as a predictor of mortality and disability in later life: a 28 -year prospective follow-up study. CMAJ. 2011;183:E235-42. http://dx.doi.org/10.1503/cmaj.100713.

30. Lehto AM, Sutela H. Three decades of working conditions. Findings of Finnish Quality of Work Life Surveys 1977-2008.
Helsinki: Statistics Finland; 2009.

31. Koskinen S, Aromaa A, Huttunen J, Teperi J, editors. Health in Finland. Helsinki: National Public Health Institute of Finland, National Research and Development Centre for Welfare and Health, Ministry of Social Affairs and Health; 2006.

32. Koivumaa-Honkanen H, Kaprio J, Honkanen RJ, Viinamäki $\mathrm{H}$, Koskenvuo M. The stability of life satisfaction in a 15 -year follow-up of adult Finns healthy at baseline. BMC Psychiatry. 2005;5:4. http://dx.doi.org/10.1186/1471-244X-5-4.

33. Järvisalo J, Andersson B, Boedeker W, Houtman I, editors. Mental Disorders as a Major Challenge in Prevention of Work Disability - Experiences in Finland, Germany, the Netherlands and Sweden. Helsinki: Kela; 2005.

34. Kujala V, Remes J, Ek E, Tammelin T, Laitinen J. Classification of Work Ability Index among young employees. Occup Med (Lond) 2005;55:399-401. http://dx.doi.org/10.1093/occmed/ kqi075.

35. Lilja R, Santamäki-Vuori T, Standing G. Unemployment and labour market flexibility: Finland. Geneva: ILO; 1990.

36. Froom P, Melamed S, Kristal-Boneh E, Benbassat J, Ribak J. Healthy volunteer effect in industrial workers. J Clin Epidemiol. 1999;52:731-5. http://dx.doi.org/10.1016/S08954356(99)00070-0.

Received for publication: 31 January 2016 